\title{
Friction Performance of Al-10\%SiCp Reinforced Metal Matrix Composites Using Taguchi Method
}

\author{
Shouvik Ghosh, Prasanta Sahoo, and Goutam Sutradhar \\ Department of Mechanical Engineering, Jadavpur University, Kolkata 700032, India \\ Correspondence should be addressed to Prasanta Sahoo; psjume@gmail.com
}

Received 27 April 2012; Accepted 25 June 2012

Academic Editors: J. Antunes and J. Wang

Copyright (C) 2013 Shouvik Ghosh et al. This is an open access article distributed under the Creative Commons Attribution License, which permits unrestricted use, distribution, and reproduction in any medium, provided the original work is properly cited.

\begin{abstract}
The present paper considers the friction performance of $\mathrm{Al}-10 \% \mathrm{SiCp}$ reinforced metal matrix composites against steel for varying tribological test parameters. The composite is prepared by stir-casting process using aluminium alloy LM6 being mixed with $10 \%$ silicon carbide by weight. The tribological tests are performed by varying applied load, sliding speed, and time. The friction performance is studied using plate-on-roller configuration in a multitribotester and optimized using Taguchi $\mathrm{L}_{27}$ orthogonal array. Analysis of variance (ANOVA) is performed to observe the significance of test parameters and their interactions on friction performance. It is observed that normal load and the interaction between normal load and speed influence the friction behaviour, significantly. The wear tracks are analyzed with the help of scanning electron microscopy.
\end{abstract}

\section{Introduction}

Particle reinforced composites are recognized as a light weight material having enhanced mechanical and tribological properties than the constituent materials. The MMC (metal matrix composite) materials attain the toughness of the alloy matrix and hardness, stiffness, and strength of the reinforcement. Researchers [1-3] have used different types of aluminium alloys for synthesis of the composites. Also, different types of silicon carbide reinforcement such as particle, whisker, and fibre reinforcement are used by researchers. Mainly reinforcement volume fraction is varied by most researchers. Ahlatci et al. [4] carried out tribological experiments by mixing reinforcement in the volume fraction range from 0 to $60 \%$. But most researchers [5-7] used volume fraction ranging from 1 to $20 \%$ for their study. The composites, synthesised by mixing the base metal and reinforcement, have greater strength, improved stiffness, improved corrosion resistance, and improved wear resistance. However, the relatively poor seizure resistance of aluminium alloy has restricted to uses in some engineering applications. These materials are good alternative to the traditional materials due to the improved properties.
The increasing use of composite materials in the automobile and aeronautics fields is due to good friction and wear properties. In aeronautics, it is used for manufacturing of rotor blades due to increased creep resistance. The aluminium composites exhibit lower friction coefficient than their base alloys [8, 9]. Iwai et al. [6] conducted the study with 2024 $\mathrm{Al}$ alloy reinforced with $10 \%$ vol SiC. The friction study showed that initially the friction coefficient value is around 0.6 for both $2024 \mathrm{Al}$ alloy and $2024 \mathrm{Al}-10 \% \mathrm{SiC}$ and then gradually decreases to 0.4. Martin et al. [9] conducted the study on $2618 \mathrm{Al}$ alloy with $15 \%$ vol $\mathrm{SiC}$ reinforcement. The materials are tested at different temperatures ranging from 0 to $200^{\circ} \mathrm{C}$. The friction coefficient value of reinforced material is less than the alloy. The friction coefficient value increases from 0.5 to 1.5 with increase in temperature for both cases. Bai et al. [10] found that friction coefficient value increased with increase in sliding time. The variation is higher for high applied load. Chen et al. [5] carried out tribological study with volume fraction range of $0-10 \%$. From this study, it was concluded that friction coefficient value increases with increase in volume fraction at lower load and values range from 0.3 to 0.8 with gradual increase in $\%$ vol. But at higher load the friction coefficient value of 
all the material ranges from 0.3 to 0.4 . Murthy et al. [11] investigated the abrasive wear behaviour of $\mathrm{Al}-\mathrm{SiC}$ whisker reinforcement of volume fraction ranging from 10 to $40 \%$. The study showed that friction coefficient value increased gradually with an increase in volume fraction, but decreased with increase in sliding distance. Chen et al. [3] carried out another study on the fretting wear behaviour and found that friction coefficient value increased from 0.16 to 0.45 for change in normal load from $5 \mathrm{~N}$ to $20 \mathrm{~N}$ and from 0.25 to 0.45 for heat treated-materials. It was also concluded that friction coefficient varies for pre-and post-heat-treated materials at lower load whereas no variation is found at higher load. Rodríguez et al. [12] conducted the study on $\mathrm{Al} / \mathrm{Li}$ alloy reinforced with $\mathrm{SiC}$ and found that the friction coefficient value of reinforced materials is higher than the alloy. Ma et al. [13] found from his experimentation that friction coefficient value increased with increase in volume fraction. A350 Al alloy showed lower coefficient value than $50 \% \mathrm{SiC}$ reinforced material. Yalcin and Akbulut [14] found that friction coefficient value decreased with increase in volume fraction and applied load. Hassan et al. [7] concluded from their study of Al- $4 \mathrm{wt} \% \mathrm{Mg}-5 \mathrm{wt} \% \mathrm{SiC}$ and $\mathrm{Al}-4 \mathrm{wt} \% \mathrm{Mg}-$ $10 \mathrm{wt} \% \mathrm{SiC}$ that the friction coefficient value is higher for both cases than the alloy metal. The composite with $10 \%$ $\mathrm{SiC}$ exhibits higher friction coefficient value. Tang et al. [15] found that monolithic $\mathrm{SiC}$ showed higher value of friction coefficient than the composite.

For the present experimental study LM6 aluminium alloy is used as base metal and silicon carbide particle ( $\mathrm{SiCp}$ ) is used as reinforcement (10\% by weight). The composite is prepared by stir-casting process in an electric melting furnace. The tribological tests are carried out on $\mathrm{Al}-10 \% \mathrm{SiCp}$ for testing the friction property of the material. The result data are analyzed by Taguchi method. Furthermore, a statistical analysis of variance (ANOVA) is performed to find the statistical significance of tribological test parameters. Finally, a confirmation test is carried out to verify the optimal process parameters obtained from the parameter design. The microstructure study is done with the help of SEM to judge the wear mode of the material.

\section{Taguchi Method}

The Taguchi method [16-18] is a powerful tool for designing high-quality systems based on orthogonal array (OA) experiments that provide much reduced variance for the experiments with an optimum setting of process control parameters. It introduces an integrated approach that is simple and efficient to find the best range of designs for quality, performance, and computational cost. This method achieves the integration of design of experiments (DOE) with the parametric optimization of the process yielding the desired results. The traditional experimental design procedures focus on the average process performance characteristics. But the Taguchi method concentrates on the effect of variation on the process quality characteristics rather than on its averages. That is, the Taguchi approach makes the process performance insensitive (robust) to variation in uncontrolled or noise factors. Taguchi recommends that this can be done by the proper design of parameters during the "parameter design" phase of offline quality control. He designed certain standard OAs by which simultaneous and independent valuation of two or more parameters for their ability to affect the variability of a particular product or process characteristic can be done in a minimum number of tests. Using OA, the Taguchi method explores the entire design space through a small number of experiments in order to determine all of the parameter effects and several of the interactions. These data are then used to predict the optimum combination of the design parameters that will minimize the objective function and satisfy all the constraints. In addition to locating a near optimum objective function, the Taguchi method provides information on parameter trends and noise sensitivities thereby enabling a robust design. The parameter design phase of the Taguchi method generally includes the following steps: (1) identifying the objective of the experiment; (2) identifying the quality characteristic (performance measure) and its measurement systems; (3) identifying the factors that may influence the quality characteristic, their levels, and possible interactions; (4) select the appropriate $\mathrm{OA}$ and assign the factors at their levels to the OA; (5) conducting the test described by the trials in the OA; (6) analysing the experimental data using the signal-to- noise $(\mathrm{S} / \mathrm{N})$ ratio, factor effects, and the analysing variance (ANOVA) to see which factors are statistically significant and to find the optimum levels of factors; (7) verifying of the optimal design parameters through confirmation experiment. The OA requires a set of wellbalanced (minimum experimental runs) experiments. The Taguchi method uses a statistical measure of performance called $(\mathrm{S} / \mathrm{N})$ ratios, which are logarithmic functions of desired output to serve as objective functions for optimization. The $\mathrm{S} / \mathrm{N}$ ratio takes both the mean and the variability into account and is defined as the ratio of the mean (signal) to the standard deviation (noise). The ratio depends on the quality characteristics of the product/process to be optimized. The three categories of $\mathrm{S} / \mathrm{N}$ ratios are used: lower the better (LB), higher the better $(\mathrm{HB})$, and nominal the best $(\mathrm{NB})$. The parameter level combination that maximizes the appropriate $\mathrm{S} / \mathrm{N}$ ratio is the optimal setting. For the case of minimization of friction, LB characteristic needs to be used. Furthermore, a statistical analysis of variance (ANOVA) is performed to find which process parameters are statistically significant. With the $\mathrm{S} / \mathrm{N}$ ratio and ANOVA analyses, the optimal combination of the process parameters can be predicted. Finally, a confirmation experiment is conducted to verify the optimal process parameters obtained from the parameter design.

\section{Experimental Details}

3.1. Fabrication Process. For the fabrication of the composite, aluminium alloy, that is, LM6, is used as matrix metal that has been reinforced with $10 \mathrm{wt} \%$ of $\mathrm{SiC}$ particles of 400 mesh size. The chemical composition of the matrix material (LM6) is given in Table 1. The material is fabricated by liquid metal stir-casting process. This process is chosen for 
TABLE 1: Chemical composition of LM6.

\begin{tabular}{lcccccccccccc}
\hline Elements & $\mathrm{Si}$ & $\mathrm{Cu}$ & $\mathrm{Mg}$ & $\mathrm{Fe}$ & $\mathrm{Mn}$ & $\mathrm{Ni}$ & $\mathrm{Zn}$ & $\mathrm{Pb}$ & $\mathrm{Sb}$ & $\mathrm{Ti}$ & $\mathrm{Al}$ \\
\hline Percentage (\%) & $10-13.0$ & 0.1 & 0.1 & 0.6 & 0.5 & 0.1 & 0.1 & 0.1 & 0.05 & 0.2 & Remaining \\
\hline
\end{tabular}

TABLE 2: Design factors with levels

\begin{tabular}{lcccc}
\hline Design factors & Unit & \multicolumn{3}{c}{ Levels } \\
& & 1 & 2 & 3 \\
\hline Load $(L)$ & $\mathrm{N}$ & 50 & $75^{\mathrm{i}}$ & 100 \\
Speed $(S)$ & $\mathrm{RPM}$ & 180 & $200^{\mathrm{i}}$ & 220 \\
Time $(T)$ & $\mathrm{MIN}$ & 20 & $30^{\mathrm{i}}$ & 40 \\
\hline
\end{tabular}

i: initial condition.

the fabrication of the composite as it is both simple and less expensive. The small ingots of LM6 are melted in clay graphite crucible using an electric resistance furnace and $3 \mathrm{wt} . \% \mathrm{Mg}$ is added with the liquid metal in order to achieve a strong bonding by decreasing the surface energy (wetting angle) between the matrix alloy and the reinforcement particles. The addition of pure magnesium also enhances the fluidity of the molten metal. Before mixing, the silicon carbide particles are preheated at $900^{\circ} \mathrm{C}$ for $2-3$ hours to make their surface oxidized. The melt is mechanically stirred by using a mild steel impeller and then the preheated silicon carbide particles are added with the stirred liquid metal. The processing of the composite is carried out at a temperature of $720^{\circ} \mathrm{C}$ with a stirring speed of $400-500 \mathrm{rpm}$. The melt is then poured at a temperature of $690^{\circ} \mathrm{C}$ into a green silica sand mould. The material is then cooled and samples for tribological testing are prepared.

3.2. Design of Experiments. Design of experiments (DOE) technique introduced by Fisher [19] is a powerful tool which allows us to carry out modelling and analysis of the influence of process variables on the response variables. The response variables are the unknown functions of the process variables also known as design factors. There are a number of control factors that can affect friction behaviour of Al-10\%SiCp. But literature review reveals that load, speed, and time are the most widespread among the researchers. Table 2 shows the design factors with their levels used in the present study. By selecting three levels, the curvature or nonlinearity effects could be studied. The friction characteristic of $\mathrm{Al}-10 \% \mathrm{SiCp}$ is studied with coefficient of friction as the response variable. The tribological test parameters are optimized with the objective of minimizing the friction coefficient.

DOE basically refers to the process of planning, designing, and analyzing the experiment so that valid and objective conclusion can be drawn effectively and efficiently. Based on Taguchi method an orthogonal array $(\mathrm{OA})$ is considered to reduce the number of experiments required to determine the optimal friction for $\mathrm{Al}-10 \% \mathrm{SiCp}$ metal matrix composite. An OA provides the shortest possible matrix of combinations in which all the parameters are varied to consider their direct effect as well as interactions simultaneously Taguchi has tabulated several standard OAs. In this investigation, a
$\mathrm{L}_{27} \mathrm{OA}$ which has 27 rows corresponding to the number of tests and 26 degrees of freedom (DOFs) with 13 columns at three levels is chosen. To check the DOFs in the experimental design, for the three level test, the three main factors take $6[3 \times(3-1)]$ DOFs. The DOF for three second-order interactions $(L \times S, L \times T, S \times T)$ is $12[3 \times(3-1) \times(3-1)]$ and the total DOFs required is 18 . As per the Taguchi method, the total DOFs of selected OA must be greater than or equal to the total DOFs required for the experiment and hence the $\mathrm{L}_{27} \mathrm{OA}$ has been selected. As per the requirements of the $\mathrm{L}_{27}$ OA, the 1st column is assigned to applied load $(L)$, the 2nd column is assigned to sliding speed (S), the 5 th column is assigned to Time $(T)$, and six columns are assigned to the twoway interactions of the first three factors while the remaining three columns are assigned for error terms. Table 3 shows the $\mathrm{OA}$ with design factors and their interactions assigned. Here, each column represents a specific factor, each row represents an experimental run, and the cell values indicate the factor settings for the run. The cell values in the main factor columns (i.e., $L, S$, and $T)$ indicate their levels $(1,2$ or 3$)$ while the same in interaction columns (two-cell fields in two columns for a particular interaction) indicate the combination of the levels of the main factors concerned. For example, the interaction $L \times S$ occupies columns 3 and 4 , and for trial no. 1 , the cell fields show 1 in column 3 and 1 in column 4 . Thus $L \times S$ has the value 11 which means, it is the combination of level 1 of $A$ and level 1 of $S$. Similarly, there are 9 such combinations $(11,22,33,12,21,23,32,13$, and 31) for $L \times S$ interaction in columns 3 and 4 . A similar procedure applies to other interaction terms as well. However, the experimental run is controlled by the settings of the controllable design factors, that is, $L, S$, and $T$, and not by the interactions. The cell values in interaction columns and error columns are used in ANOVA for determination of their percentage contribution to the total effect. In this case, if the full factorial design was used, it would have $3^{3}=27$ runs for consideration of even the three main factors only. The $\mathrm{L}_{27} \mathrm{OA}$ requires only 27 runs-a fraction of the full factorial design-for consideration of main factors along with the interactions. This array is orthogonal; factor levels are weighted equally across the entire design.

3.3. Tribological Test. The tribological tests are carried out in a plate on roller multitribotester TR25 (Ducom, India) (Figure 1). It is used to measure the friction of $\mathrm{Al}-10 \% \mathrm{SiCp}$ under dry nonlubricated condition and at ambient temperature $\left(28^{\circ} \mathrm{C}\right)$ and relative humidity of about $85 \%$. The Al-10\% SiC samples (size $20 \mathrm{~mm} \times 20 \mathrm{~mm} \times 8 \mathrm{~mm}$ ) are pressed against a rotating steel roller (diameter $50 \mathrm{~mm}$, thickness $50 \mathrm{~mm}$, and material EN8 steel) of hardness $55 \mathrm{HRc}$. The setup is placed in such a way that the rotating roller serves as the counter face material and stationary plate serves as the test specimen. A $1: 5$ ratio loading lever is used to apply normal load on top 
TABLE 3: $\mathrm{L}_{27}$ orthogonal array with design factors.

\begin{tabular}{|c|c|c|c|c|c|c|c|c|c|c|c|c|c|}
\hline \multicolumn{14}{|c|}{ Column } \\
\hline Trial no. & 1 & 2 & 3 & 4 & 5 & 6 & 7 & 8 & 9 & 10 & 11 & 12 & 13 \\
\hline 11101 no. & $(L)$ & $(S)$ & $(L \times S)$ & $(L \times S)$ & $(T)$ & $(L \times T)$ & $(L \times T)$ & $(S \times T)$ & - & - & $(S \times T)$ & - & - \\
\hline 1 & 1 & 1 & 1 & 1 & 1 & 1 & 1 & 1 & 1 & 1 & 1 & 1 & 1 \\
\hline 2 & 1 & 1 & 1 & 1 & 2 & 2 & 2 & 2 & 2 & 2 & 2 & 2 & 2 \\
\hline 3 & 1 & 1 & 1 & 1 & 3 & 3 & 3 & 3 & 3 & 3 & 3 & 3 & 3 \\
\hline 4 & 1 & 2 & 2 & 2 & 1 & 1 & 1 & 2 & 2 & 2 & 3 & 3 & 3 \\
\hline 5 & 1 & 2 & 2 & 2 & 2 & 2 & 2 & 3 & 3 & 3 & 1 & 1 & 1 \\
\hline 6 & 1 & 2 & 2 & 2 & 3 & 3 & 3 & 1 & 1 & 1 & 2 & 2 & 2 \\
\hline 7 & 1 & 3 & 3 & 3 & 1 & 1 & 1 & 3 & 3 & 3 & 2 & 2 & 2 \\
\hline 8 & 1 & 3 & 3 & 3 & 2 & 2 & 2 & 1 & 1 & 1 & 3 & 3 & 3 \\
\hline 9 & 1 & 3 & 3 & 3 & 3 & 3 & 3 & 2 & 2 & 2 & 1 & 1 & 1 \\
\hline 10 & 2 & 1 & 2 & 3 & 1 & 2 & 3 & 1 & 2 & 3 & 1 & 2 & 3 \\
\hline 11 & 2 & 1 & 2 & 3 & 2 & 3 & 1 & 2 & 3 & 1 & 2 & 3 & 1 \\
\hline 12 & 2 & 1 & 2 & 3 & 3 & 1 & 2 & 3 & 1 & 2 & 3 & 1 & 2 \\
\hline 13 & 2 & 2 & 3 & 1 & 1 & 2 & 3 & 2 & 3 & 1 & 3 & 1 & 2 \\
\hline 14 & 2 & 2 & 3 & 1 & 2 & 3 & 1 & 3 & 1 & 2 & 1 & 2 & 3 \\
\hline 15 & 2 & 2 & 3 & 1 & 3 & 1 & 2 & 1 & 2 & 3 & 2 & 3 & 1 \\
\hline 16 & 2 & 3 & 1 & 2 & 1 & 2 & 3 & 3 & 1 & 2 & 2 & 3 & 1 \\
\hline 17 & 2 & 3 & 1 & 2 & 2 & 3 & 1 & 1 & 2 & 3 & 3 & 1 & 2 \\
\hline 18 & 2 & 3 & 1 & 2 & 3 & 1 & 2 & 2 & 3 & 1 & 1 & 2 & 3 \\
\hline 19 & 3 & 1 & 3 & 2 & 1 & 3 & 2 & 1 & 3 & 2 & 1 & 3 & 2 \\
\hline 20 & 3 & 1 & 3 & 2 & 2 & 1 & 3 & 2 & 1 & 3 & 2 & 1 & 3 \\
\hline 21 & 3 & 1 & 3 & 2 & 3 & 2 & 1 & 3 & 2 & 1 & 3 & 2 & 1 \\
\hline 22 & 3 & 2 & 1 & 3 & 1 & 3 & 2 & 2 & 1 & 3 & 3 & 2 & 1 \\
\hline 23 & 3 & 2 & 1 & 3 & 2 & 1 & 3 & 3 & 2 & 1 & 1 & 3 & 2 \\
\hline 24 & 3 & 2 & 1 & 3 & 3 & 2 & 1 & 1 & 3 & 2 & 2 & 1 & 3 \\
\hline 25 & 3 & 3 & 2 & 1 & 1 & 3 & 2 & 3 & 2 & 1 & 2 & 1 & 3 \\
\hline 26 & 3 & 3 & 2 & 1 & 2 & 1 & 3 & 1 & 3 & 2 & 3 & 2 & 1 \\
\hline 27 & 3 & 3 & 2 & 1 & 3 & 2 & 1 & 2 & 1 & 3 & 1 & 3 & 2 \\
\hline
\end{tabular}

specimen. The loading lever is pivoted near the normal load sensor and carries a counter weight at one end while at the other end a loading pan is suspended for placing the dead weights. The frictional force is measured by a frictional force sensor that uses a beam type load cell of capacity $1000 \mathrm{~N}$. The friction tests are carried out at different load and speed for different interval of time as mentioned in Table 2.

3.4. Microstructure Study. After friction tests, scanning electron microscopy (SEM) is used to evaluate the microstructure of the specimens. The microstructure study is conducted to know the nature of the wear tracks. A scanning electron microscope (JEOL, JSM-6360) is used for the microstructure study of the material.

\section{Results and Discussion}

The aim of the present study is to minimize friction of Al$10 \% \mathrm{SiCp}$ by optimizing the tribo-testing parameters with the help of Taguchi method. The influence of tribological testing parameters like applied load, sliding speed, and sliding duration together with their interactions on the friction behaviour of $\mathrm{Al}-10 \% \mathrm{SiCp}$ is studied. Since the study is related to friction, coefficient of friction is taken as system response. Accordingly, the effect of the tribo-testing conditions on the friction behaviour of $\mathrm{Al}-10 \% \mathrm{SiCp}$ is studied.

4.1. Analysis of Signal-to-Noise Ratio. The desirable factor levels are calculated by simple average of the results. This traditional method is not able to capture the variability of the results within the trial condition. Thus the $S / N$ ratio analysis is done in this study with the friction coefficient as the performance index. The $S / N$ ratio for friction coefficient is calculated using LB criterion and the same is given by

$$
\mathrm{S} / \mathrm{N}=-10 \log \frac{1}{n} \sum y^{2},
$$

where $y$ is the observed data and $n$ is the number of observations. Table 4 shows the experimental results for friction coefficient and the corresponding $\mathrm{S} / \mathrm{N}$ ratio. The orthogonal experimental design enables it to separate out the effect of each tribological parameter at different levels. For example, the mean $\mathrm{S} / \mathrm{N}$ ratio for factor $L$ (Load) at levels 1,2 , and 3 can be calculated by averaging the $\mathrm{S} / \mathrm{N}$ ratios 


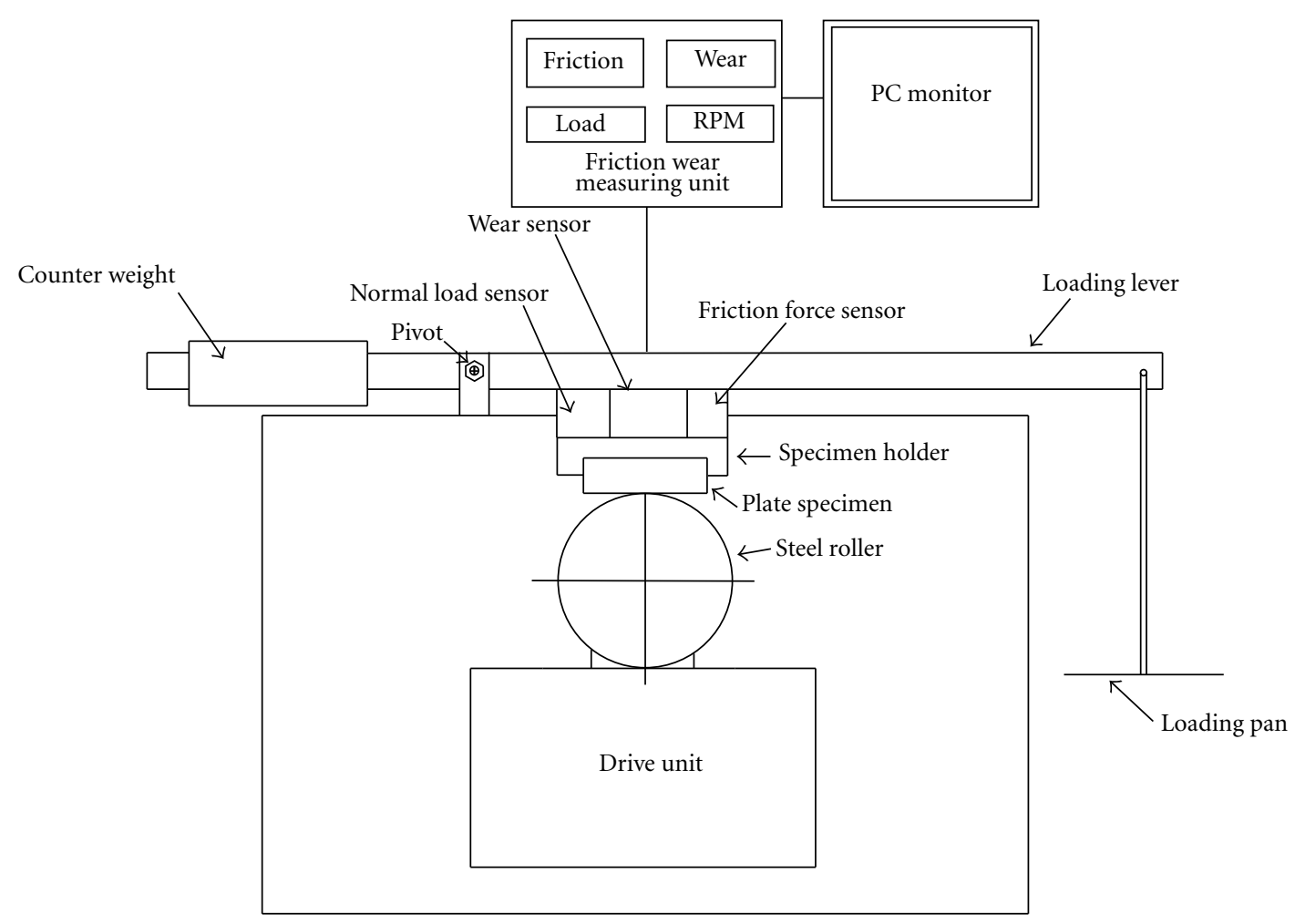

FIGURE 1: Schematic diagram of Multitribotester.

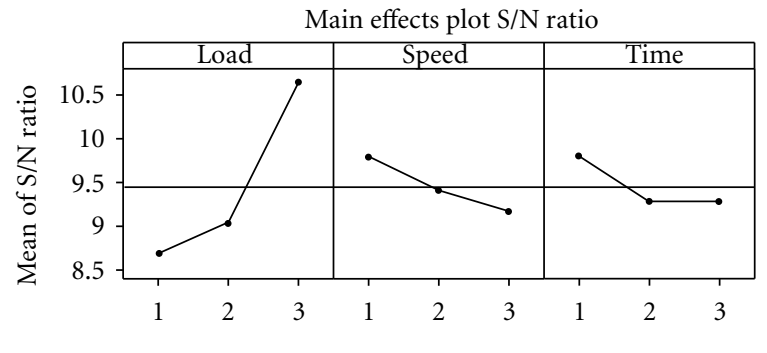

FIgURE 2: Main effects plot.

for the experiments $1-9,10-18$, and 19-27, respectively. The mean $\mathrm{S} / \mathrm{N}$ ratio for each level of the other factors can be computed in the similar manner. The mean $\mathrm{S} / \mathrm{N}$ ratio for each level of the factors $L, S$, and $T$ is summarized and called the response table for friction coefficient (Table 5). In addition, the total mean $\mathrm{S} / \mathrm{N}$ ratio for the 27 experiments is also calculated and listed in Table 5 . All the calculations are performed using Minitab [20]. The response table shows the average of the selected characteristic for each level of the factors. The response table includes ranks based on Delta statistics, which compares the relative magnitude of effects. The Delta statistic is the highest average for each factor minus the lowest average for the same. Ranks are assigned based on Delta values; rank 1 is assigned to the highest Delta value, rank 2 to the second highest Delta value, and so on. The corresponding main effects and interaction effects plots between the process parameters are also shown in Figures
2 and 3, respectively. The significance of each parameter is determined from the inclination of the main effects plot. A parameter for which the line has the highest inclination will have the most significant effect. It is very much clear from the main effects plot that parameter $L$ (applied load) is the most significant parameter while parameter $S$ (sliding speed) also has some significant effect. To study an interaction plot means to determine the nonparallelism of parameter effects. If the lines of an interaction plot are not parallel, it suggests that there is nominal interaction occurred and if the lines intersect each other, then strong interactions occurred between the parameters. Figure 3 shows that there is strong interaction between the parameters $L$ and $S$ while there is moderate interaction between the parameters $L$ and $T$ and between $S$ and $T$. Thus from the present analysis, it is clear that the applied load $(L)$ is the most influencing parameter for friction characteristics of $\mathrm{Al}-10 \% \mathrm{SiCp}$ metal matrix composites. The optimal process parameter combination is the one that yields maximum mean $\mathrm{S} / \mathrm{N}$ ratio and thus, the same for minimum friction coefficient is found to be L3S1T1, that is, the highest level of normal load and lowest levels of speed and time.

4.2. Analysis of Variance (ANOVA). ANOVA is a statistical technique which can provide some important conclusions based on analysis of the experimental data. This method is very useful for revealing the level of significance of the influence of factor(s) or interaction of factors on a particular response. It separates the total variability of the response into contributions of each of the factors and the error. 

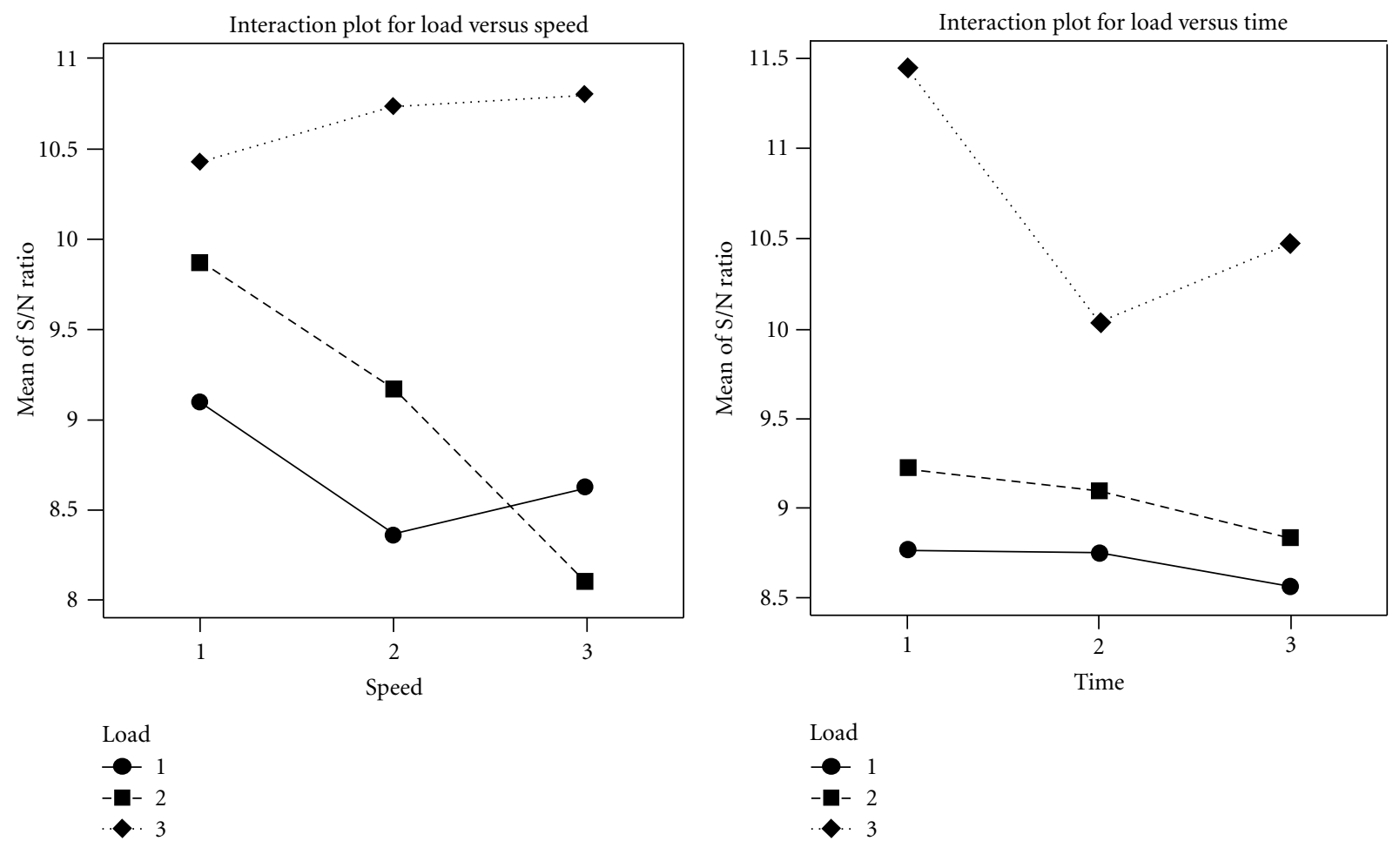

(a)

(b)

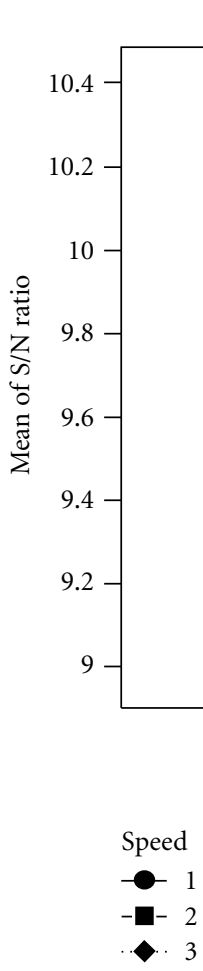

Interaction plot for speed versus time

Load
$-\mathbf{-} 1$
$-\mathbf{-} 2$
-3

(c)

FIGURE 3: Interaction plots: (a) load versus speed, (b) load versus time, and (c) speed versus time. 
TABLE 4: Friction test results.

\begin{tabular}{lcc}
\hline Trial no. & COF & S/N ratio \\
\hline 1 & 0.353 & 9.0445 \\
2 & 0.356 & 8.9710 \\
3 & 0.344 & 9.2688 \\
4 & 0.392 & 8.1343 \\
5 & 0.371 & 8.6125 \\
6 & 0.383 & 8.3360 \\
7 & 0.350 & 9.1186 \\
8 & 0.369 & 8.6595 \\
9 & 0.394 & 8.0901 \\
10 & 0.314 & 10.061 \\
11 & 0.322 & 9.8429 \\
12 & 0.328 & 9.6825 \\
13 & 0.331 & 9.6034 \\
14 & 0.348 & 9.1684 \\
15 & 0.366 & 8.7304 \\
16 & 0.399 & 7.9805 \\
17 & 0.386 & 8.2683 \\
18 & 0.395 & 8.0681 \\
19 & 0.258 & 11.768 \\
20 & 0.318 & 9.9515 \\
21 & 0.333 & 9.5511 \\
22 & 0.271 & 11.341 \\
23 & 0.320 & 9.8970 \\
24 & 0.284 & 10.934 \\
25 & 0.275 & 11.213 \\
26 & 0.308 & 10.229 \\
27 & 0.284 & 10.934 \\
\hline & & \\
& &
\end{tabular}

TABLE 5: Response table for friction coefficient.

\begin{tabular}{lccc}
\hline Level & Load & Speed & Time \\
\hline 1 & 8.693 & 9.793 & 9.807 \\
2 & 9.045 & 9.417 & 9.289 \\
3 & 10.646 & 9.173 & 9.288 \\
Rank & 1 & 2 & 3 \\
Delta & 1.954 & 0.620 & 0.519 \\
\hline
\end{tabular}

Total mean $\mathrm{S} / \mathrm{N}$ ratio $=9.461 \mathrm{~dB}$.

Using Minitab [20], ANOVA is performed to determine which parameter and interaction significantly affect the performance characteristics. Table 6 shows the ANOVA result for friction coefficient of $\mathrm{Al}-10 \% \mathrm{SiCp}$. ANOVA calculates the $F$-ratio, which is the ratio between the regression mean square and the mean square error. The $F$-ratio, also called the variance ratio, is the ratio of variance due to the effect of a factor and variance due to the error term. This ratio is used to measure the significance of the parameters under investigation with respect to the variance of all the terms included in the error term at the desired significance level, $\alpha$. If the calculated value of the $F$-ratio is higher than the tabulated value of the $F$-ratio, then the factor is significant at a desired $\alpha$ level. In general, when the $F$ value increases,

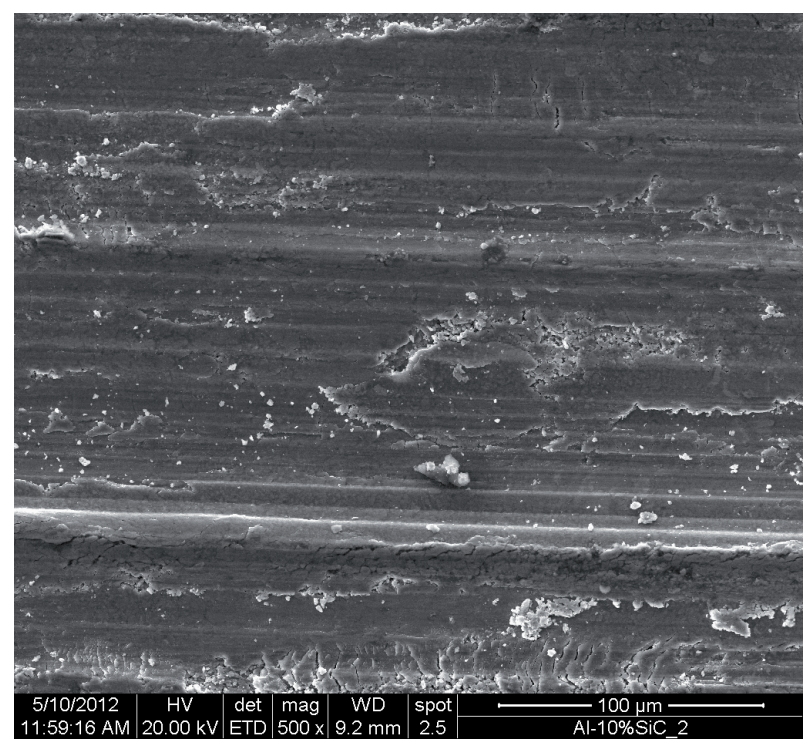

FIGURE 4: SEM image of worn surface of Al-10\%SiCp composite.

the significance of the parameter also increases. The ANOVA table shows the percentage contribution of each parameter. It is seen that parameter $L$, that is, applied load has the most significant influence on friction coefficient at the confidence level of $99 \%$ while parameters $S$ (sliding speed) and $T$ (Time) is significant only at a $90 \%$ confidence level within the specific test range. Similarly, the interaction of parameters $L \times S$ has strong influence on friction property of the composite.

4.3. Confirmation Test. After the optimal level of testing parameters have been found, it is necessary that verification tests are carried out in order to evaluate the accuracy of the analysis and to validate the experimental results. The estimated $\mathrm{S} / \mathrm{N}$ ratio $\hat{\eta}$, using the optimal level of the testing parameters can be calculated as

$$
\widehat{\eta}=\eta_{m}+\sum_{i=1}^{o}\left(\bar{\eta}_{i}-\eta_{m}\right)
$$

where, $\eta_{m}$ is the total mean $\mathrm{S} / \mathrm{N}$ ratio, $\bar{\eta}_{i}$ is the mean $\mathrm{S} / \mathrm{N}$ ratio at the optimal testing parameter level, and $o$ is the number of main design process parameters that significantly affect the friction performance of $\mathrm{Al}-10 \% \mathrm{SiCp}$.

Table 7 shows the comparison of the estimated friction coefficient with the actual friction coefficient using the optimal condition. Good agreement seems to take place between the estimated and actual friction coefficient. The improvement of $\mathrm{S} / \mathrm{N}$ ratio from initial to optimal condition is $2.5992 \mathrm{~dB}$ which means there is a reduction of $28 \%$ in friction coefficient of Al-SiCp MMC.

4.4. Microstructure Study. Figure 4 shows the SEM micrograph of the wear surface of the Al-10\%SiCp composite. The SEM micrograph exhibits longitudinal grooves and partial irregular pits which indicates adhesive wear. The presence of grooves indicates the microcutting and microploughing 
TABLE 6: ANOVA table for coefficient of friction.

\begin{tabular}{lccccc}
\hline Source & DF & SS & MS & $F$ & Contribution (\%) \\
\hline$L$ & 2 & 19.51 & 9.76 & $39.61^{\#}$ & 63.20 \\
$S$ & 2 & 1.76 & 0.86 & $3.56^{*}$ & 5.69 \\
$T$ & 2 & 1.61 & 0.81 & $3.28^{*}$ & 5.23 \\
$L * S$ & 4 & 4.01 & 1.01 & $4.06^{\wedge}$ & 12.96 \\
$L * T$ & 4 & 1.83 & 0.46 & 0.19 & 5.94 \\
$S * T$ & 4 & 0.19 & 0.05 & & 0.60 \\
Error & 8 & 1.98 & 0.25 & & 6.38 \\
\hline Total & 26 & 30.89 & & & 100 \\
\hline
\end{tabular}

Significant parameters and interactions $\left({ }^{\sharp} F_{0.01,2,8}=8.65 ;{ }^{*} F_{0.10,2,8}=3.11 ;{ }^{\wedge} F_{0.05,4,8}=3.84\right)$.

TABLE 7: Confirmation result table.

\begin{tabular}{lccc}
\hline & \multirow{2}{*}{ Initial parameter } & \multicolumn{2}{c}{ Optimal parameter } \\
& & Predicted & Experimental \\
\hline Level & L2S2T2 & L3S1T1 & L3S1T1 \\
COF & 0.348 & & 0.258 \\
S/N ratio $(\mathrm{dB})$ & 9.1684 & 11.3243 & 11.7676 \\
\hline
\end{tabular}

Improvement of $\mathrm{S} / \mathrm{N}$ ratio $=2.5992 \mathrm{~dB}$.

effect of the counterface while pits or prows are indicative of adhesive failure of $\mathrm{Al}-10 \% \mathrm{SiCp}$ composite. The adhesion occurs under the experimental conditions used that induced a substantial attractive force between the mating surfaces leading to a high mutual solubility of aluminium and iron. Hence, the wear phenomenon encountered in case of Al-SiCp composite is both abrasive and adhesive.

In the present study, the influence of three factors, That is, applied load, sliding speed and time on the friction behaviour of Al-SiCp composite is studied. Some other factors like heat treatment, temperature, volume fraction of reinforcement, and so forth are considered to be constant in this investigation. In future studies, an attempt will be made to evaluate the effect of these factors on the friction behaviour of the composite.

\section{Conclusions}

The friction performance of $\mathrm{Al}-10 \% \mathrm{SiCp}$ reinforced metal matrix composites against steel is studied for varying tribological test parameters. The optimal tribological testing combination for minimum friction is found to be L3S1T1, that is, the highest level of normal load and lowest levels of speed and time. All the factors applied load $(L)$, speed $(S)$, and time $(T)$ are found to affect the friction significantly. But the factor load $(L)$ is the most important factor with a contribution of $63.20 \%$. The interaction between load and speed $(L \times S)$ is found to be the most significant interaction. From the confirmation test, it is found that the improvement of $\mathrm{S} / \mathrm{N}$ ratio from initial to optimal testing condition for optimization of coefficient of friction is $2.5992 \mathrm{~dB}$, which means there is a decrease of $28 \%$ for coefficient of friction. From the microstructure study of the wear tracks, it is observed that both abrasive and adhesive wear are encountered.

\section{References}

[1] M. Bai, Q. Xue, X. Wang, Y. Wan, and W. Liu, "Wear mechanism of SiC whisker-reinforced 2024 aluminum alloy matrix composites in oscillating sliding wear tests," Wear, vol. 185, no. 1-2, pp. 197-202, 1995.

[2] A. Onat, "Mechanical and dry sliding wear properties of silicon carbide particulate reinforced aluminium-copper alloy matrix composites produced by direct squeeze casting method," Journal of Alloys and Compounds, vol. 489, no. 1, pp. 119-124, 2010.

[3] R. Chen, A. Iwabuchi, and T. Shimizu, "The effect of a T6 heat treatment on the fretting wear of a SiC particle-reinforced A356 aluminum alloy matrix composite," Wear, vol. 238, no. 2, pp. 110-119, 2000.

[4] H. Ahlatci, E. Candan, and H. Cimenoglu, "Abrasive wear behavior and mechanical properties of Al-Si/SiC composites," Wear, vol. 257, no. 5-6, pp. 625-632, 2004.

[5] R. Chen, A. Iwabuchi, T. Shimizu, H. S. Shin, and H. Mifune, "The sliding wear resistance behavior of $\mathrm{NiAl}$ and $\mathrm{SiC}$ particles reinforced aluminum alloy matrix composites," Wear, vol. 213, no. 1-2, pp. 175-184, 1997.

[6] Y. Iwai, H. Yoneda, and T. Honda, "Sliding wear behavior of SiC whisker-reinforced aluminum composite," Wear, vol. 181-183, no. 2, pp. 594-602, 1995.

[7] A. M. Hassan, A. Alrashdan, M. T. Hayajneh, and A. T. Mayyas, "Wear behavior of Al-Mg-Cu-based composites containing SiC particles," Tribology International, vol. 42, no. 8, pp. 1230-1238, 2009.

[8] F. Akhlaghi and A. Zare-Bidaki, "Influence of graphite content on the dry sliding and oil impregnated sliding wear behavior of Al 2024-graphite composites produced by in situ powder metallurgy method," Wear, vol. 266, no. 1-2, pp. 37-45, 2009.

[9] A. Martín, M. A. Martínez, and J. Llorca, "Wear of SiCreinforced Al-matrix composites in the temperature range $20--2000^{\circ}$ C, 'Wear, vol. 193, no. 2, pp. 169-179, 1996.

[10] M. Bai, Q. Xue, and Q. Ge, "Wear of $2024 \mathrm{Al}-\mathrm{Mo}-\mathrm{SiC}$ composites under lubrication,” Wear, vol. 195, no. 1-2, pp. 100-105, 1996.

[11] V. S. R. Murthy, K. Srikanth, and C. B. Raju, "Abrasive wear behaviour of $\mathrm{SiC}$ whisker-reinforced silicate matrix composites," Wear, vol. 223, no. 1-2, pp. 79-92, 1998.

[12] J. Rodríguez, P. Poza, M. A. Garrido, and A. Rico, "Dry sliding wear behaviour of aluminium-lithium alloys reinforced with SiC particles," Wear, vol. 262, no. 3-4, pp. 292-300, 2007.

[13] T. Ma, H. Yamaura, D. A. Koss, and R. C. Voigt, "Dry sliding wear behavior of cast SiC-reinforced Al MMCs," Materials Science and Engineering A, vol. 360, no. 1-2, pp. 116-125, 2003. 
[14] Y. Yalcin and H. Akbulut, "Dry wear properties of A356-SiC particle reinforced MMCs produced by two melting routes," Materials and Design, vol. 27, no. 10, pp. 872-881, 2006.

[15] H. Tang, X. Zeng, X. Xiong, L. Li, and J. Zou, "Mechanical and tribological properties of short-fiber-reinforced $\mathrm{SiC}$ composites," Tribology International, vol. 42, no. 6, pp. 823-827, 2009.

[16] G. Taguchi, Introduction to Quality Engineering, Asian Productivity Organization, 1990.

[17] P. J. Ross, Taguchi Technique for Quality Engineering, McGrawHill, New York, NY, USA, 2nd edition, 1996.

[18] R. K. Roy, A Primer on Taguchi Method, Van Nostraid Reinhold, New York, NY, USA, 1990.

[19] R. A. Fisher, Design of Experiments, Oliver \& Boyd, Edinburgh, UK, 1951.

[20] Minitab User Manual (Release 13.2), Making Data Analysis Easier, MINITAB, State College, Pa, USA, 2001. 

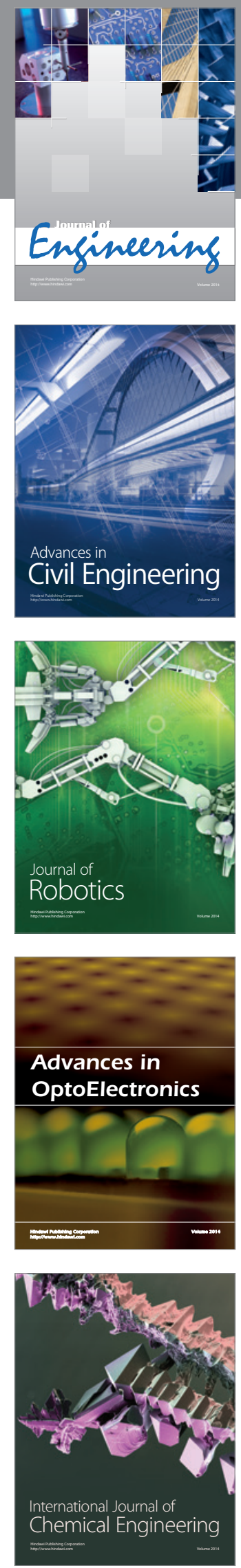

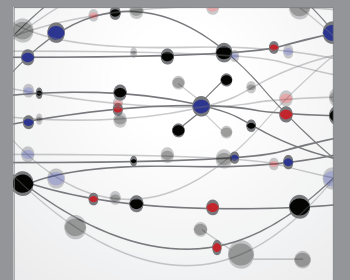

The Scientific World Journal
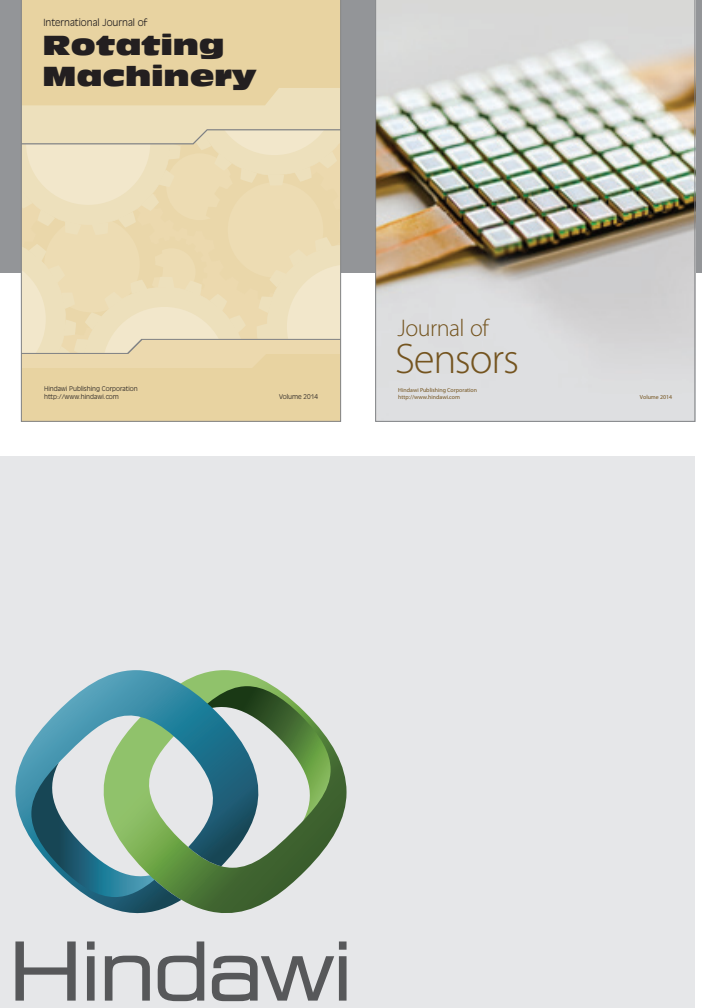

Submit your manuscripts at http://www.hindawi.com
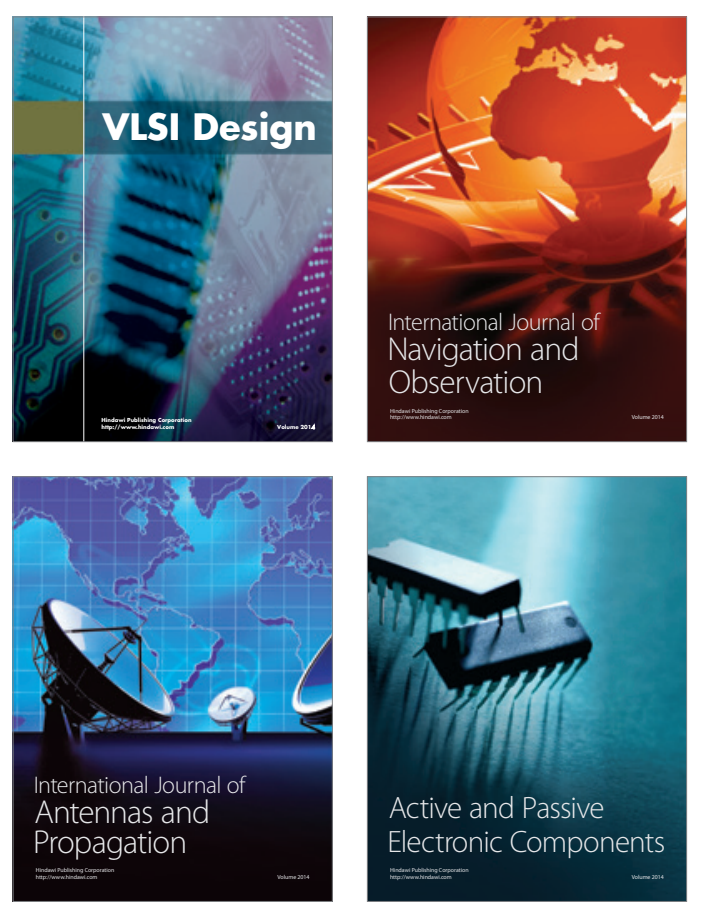
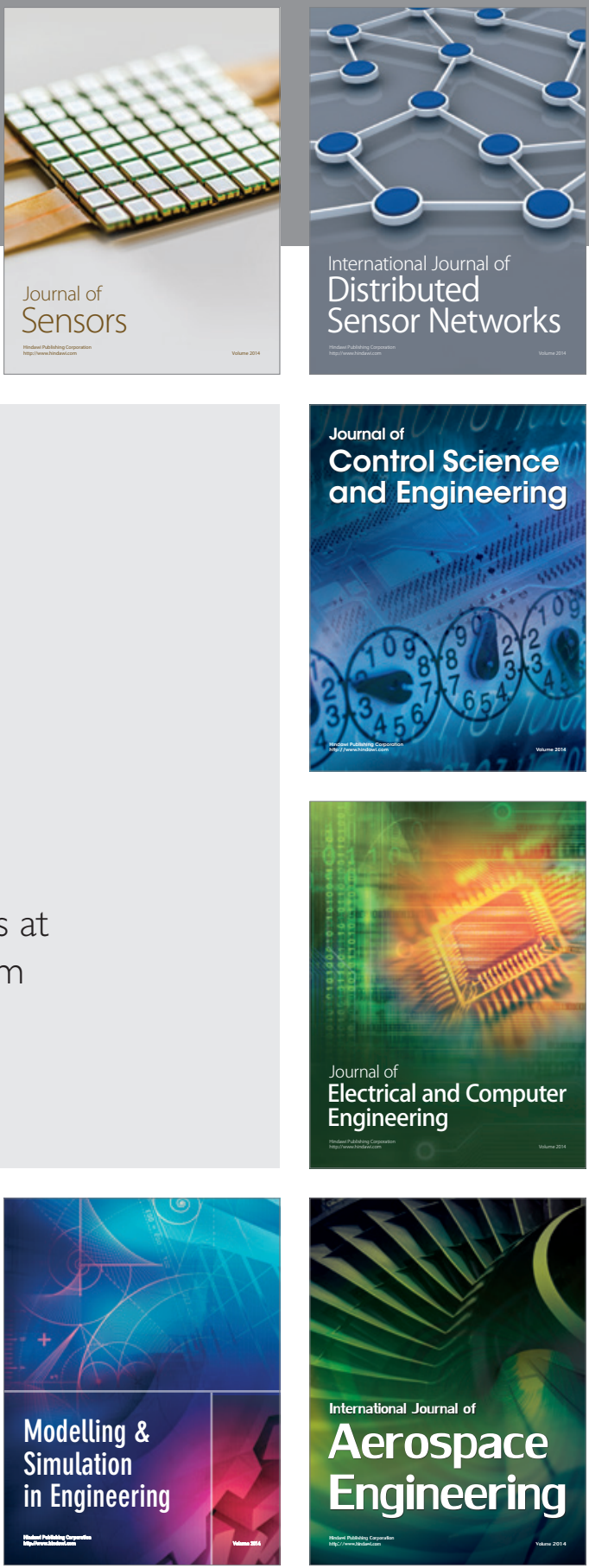

Journal of

Control Science

and Engineering
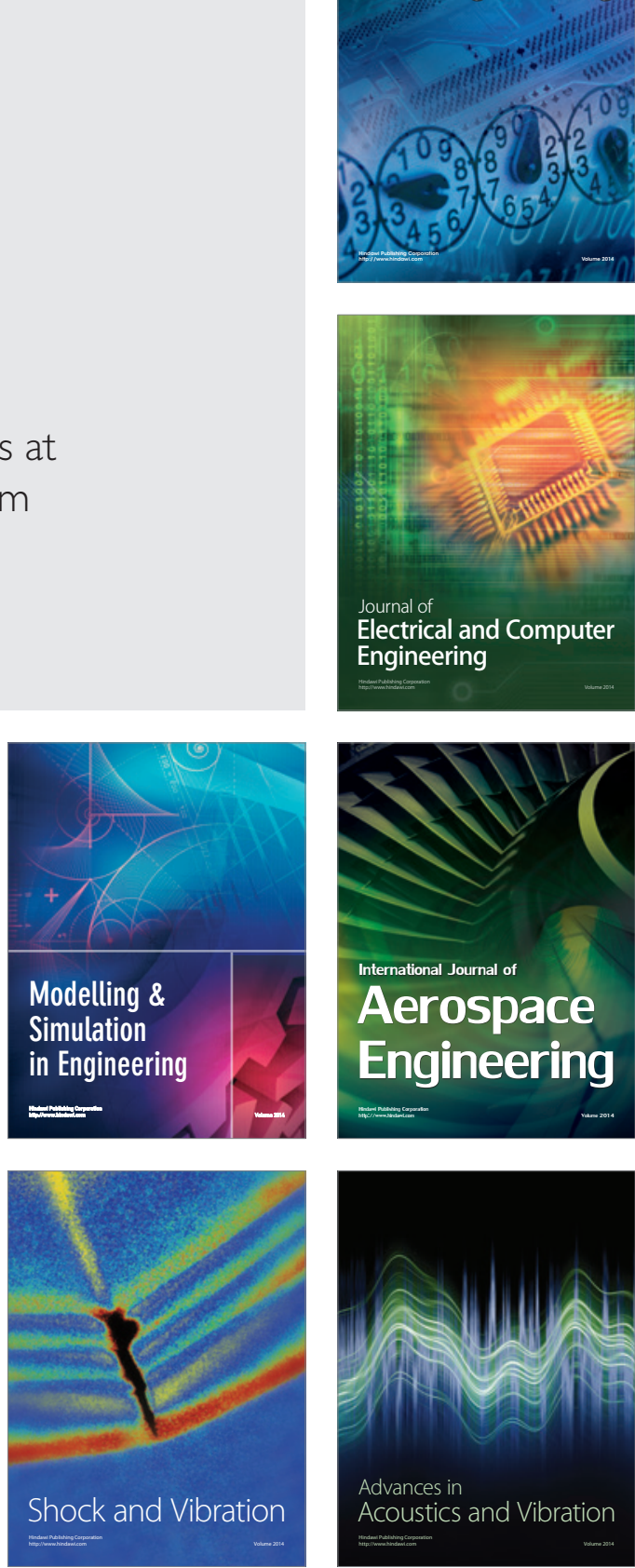